\title{
Bio-inoculants as Prospective Inputs for Achieving Sustainability: Indian Story
}

\author{
Chinmay Gupta ${ }^{1}$, Mahesh Kumar Yadav ${ }^{1}$, Vishram Meena ${ }^{1}$, Ambuj Singh ${ }^{1}$, H.B. Singh ${ }^{2}$, \\ B.K. Sarma ${ }^{2}$, S.P. Singh ${ }^{2}$ and Amitava Rakshit ${ }^{1 *}$
}

\begin{abstract}
${ }^{1}$ Department of Soil Science and Agricultural Chemistry, Institute of Agricultural Sciences, Banaras Hindu University, Varanasi 221005, Uttar Pradesh, India

${ }^{2}$ Department of Mycology and Plant Pathology, Institute of Agricultural Sciences, Banaras Hindu University, Varanasi 221005, Uttar Pradesh, India
\end{abstract}

*Corresponding author: amitavar@bhu.ac.in (ORCID ID: 0000-0002-9406-8262)

Received: $11-09-2019$

Revised: $20-01-2020$

Accepted: 25-02-2020

\begin{abstract}
Increasing consumption of synthetic chemical fertilizers played a great role in alleviating hunger but has also resulted in some adverse effects on natural resources like disaster in soil quality and conceivable outcomes of water pollution. Due to these unfavorable effects, emphasis is being laid on alternate forms of agriculture that are more sustainable. The development of bioinoculant with multi-crop growth promoting activities is most important for sustenance of agriculture. Instead of being financially viable and ecoaccommodating in nature, a few imperatives incorporate temperamental supplies and non-appearance of appropriate quality control limit the application or execution of the innovation. In the present review status, use and major manufacturer /industries involved for production of bioinoculants in India has been presented. The total number of units including public, private and cooperatives estimated to be 297. Maharashtra is having the highest number of private companies (68) followed by Gujarat (56) while Tamil Nadu have the highest number public sector units (7) and Delhi is having highest number of cooperatives units (3). Production data (carrier base in MT) revealed that Gujarat (6575 MT) topped the list first followed by Madhya Pradesh and Karnatka (2589.9 MT) during 2016-17. Zone wise bio-fertilizer production in India during the same period is highest in Karnatka both in carrier based formulation (31553.06 MT) and liquid based formulation (993.443 KL).

\section{Highlights}

( Complementary use of bio-fertilizers and organic matter in suitable combinations with chemical fertilizers is the only way out in the present set of frgile agro ecosystem.

(0) The global market for biofertilizers is expected to exceed a market worth of USD 10.2 billion by 2018.

0 Western parts of India is having more concentration of private companies while southern states is having the highest number public sector units and central part of India is having highest number of co-operatives units.

( Key issue in formulation development and production of bioinoculant is the quality control of the products.
\end{abstract}

Keywords: Fertilizers, bioinoculant, Karnatka, soil, agriculture

The green revolution bought amazing consequences in food grain production (283.7 MT during 201819) but with insufficient concern for agriculture and environmental sustainability. Sustainable agriculture is proving as one of the toughest jobs in these days. There is no uniformity in agriculture practices all over the world, but one thing which

How to cite this article: Gupta, C., Yadav, M.K., Meena, V., Singh, A., Singh, H.B., Sarma, B.K., Singh, S.P. and Rakshit, A. (2020). Bio-inoculants as prospective inputs for achieving sustainability: Indian story, Economic Affairs, 65(1): 31-41. 
is more or less common is the use of chemical pesticides and fertilizers causing agriculture fatigue. Therefore, it is a matter of concern to overcome nutritional effects through the help of intensification of agriculture with the use of chemical fertilizers, broad spectrum pesticides. Due to the necessity to reduce chemical products (chemical fertilizers, pesticides, and supplements), it's the moral responsibility aiming sustainable agriculture and protecting the environment. Integrated plant nutrient management is an important component through rational use of existing technology for sustainable agriculture. The best available options lie in the complementary use of bio-fertilizers and organic matter in suitable combinations with chemical fertilizers (Rakshit et al. 2014). The efficient bio-fertilizers are gaining importance in sustaining agriculture as bio-inoculants may be the most viable option to overcome from agriculture fatigue due to various complementing combinations of microbial inoculants for management of major nutrients are necessary for agriculture sustainability which are more robust than synthetic chemicals as the formulation product of a single microbe may involve direct interactions with pathogens, and numerous mechanisms take part in disease suppression and plant growth promotion (Rodrigo et al. 2011; Bhardwaj et al. 2014; Rakshit et al. 2014).

Bio fertilizers are related commonly to plant growth promotion and responses to abioticstresses, induced by a pool of bioactive compounds from a great diversity of environment friendly sources (Barman et al. 2017; Meena et al. 2017). The beneficial bacteria can produce phytohormones and other compounds (Borriss 2011), biomasses and their extracts, e.g., algae (Jannin et al. 2013) and yeast (Lonhienne et al. 2014), or by mycorrhizal fungi (Bettoni et al. 2014), even products obtained by fermentation as amino acid sources (Civiero et al. 2013), among a huge diversity of sources that nature and the biotechnology can offer. Leguminouscrop fixes the atmospheric nitrogen by Rhizobium which requires optimum levelof phosphorus in plant tissue. Mineral solubilizers play an important role in seedlingsetting because more of the tropical soils are phosphate fixing and make itunavailable to the plants. Phosphate-solubilizing microorganisms (PSMs) thatsolubilize bound form of phosphorus and AM fungi act as uptaker of phosphorusand make it available to the host plants. Microorganisms facilitate plant mineral nutrition by changing the amounts, concentrations and properties of minerals available to plants.

\section{Status of bioinoculant production}

\section{Global scenario}

The growth in the organic food market is a major driving force for the increasing trends in the global biofertilizers and biopesticides market. The reason for this advancement is due to the fact that future organic industry is strongly dependent upon the crop promotion and protection products free of chemicals.

The global market for biofertilizers in terms of revenue was estimated to amount to about 5 billion USD in 2011. The Asia-Pacific region was responsible for approximately $34 \%$ of the total demand in 2011. According to a detailed analysis of the current market and of the scenarios for its development in different continents, it is forecasted to double by 2017, actively in Latin America, India and China. The global market for biofertilizers is expected to exceed a market worth of USD 10.2 billion by 2018. The global biofertilizers market size valued at USD 1.34 billion in 2018 and is projected to reach USD 3.18 billion by the end of 2026, exhibiting a compound annual growth rate (CAGR) of $11.3 \%$ Dec. 2019, (https://www.fortunebusinessinsights. com/industry-reports/biofertilizers-market-100413,). Latin America is currently among the top consumers of biofertilizers: in Mexico, a programme to support the introduction of nitrogen-fixing biofertilizers based on Azospirillum was carried on 1.5 million hectares. According to estimates of the Indian National Biofertilizer Development Center (NBDC) and the Bio-Tech Consortium of India Ltd (BCIL), about 350.000-500.000 tonnes of biofertilizers are potentially required for Indian agriculture. European and Latin American countries are the leading consumers of biofertilizers, owing to the stringent regulations imposed to chemical fertilizers, which tend to be replaced by biofertilizers (source: https://www.bio-fit.eu/q3/lo10-bio-fertilizerstechnology-\%E2\%80\%93-awareness,-marketing-andfuture? showall=1).

\section{Indian scenario}

As we know that the Indian government has drawn 
its considerations lately in comparison of developed country but had put big initiatives in collaboration with national institutes to look forth and contributes enhancement of biofertilizer productions. Indian biofertilizer market had grown rapidly in the period of financial year 2009 till today, the production of biofertilizers in India had more than tripled during 2009-18. The growth is expected to continue in future owing to the strong push by the Government of India (GoI) to promote bio-agriculture. Maharashtra is having highest no. of companies (68) followed by Gujarat (56) as shown in Fig. 1.

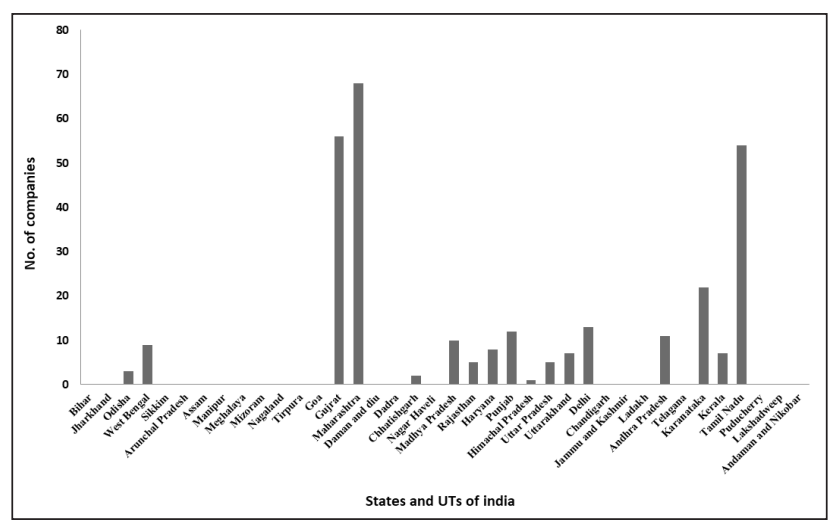

Fig. 1: Number of private companies engaged for producing bio fertilizers in different states of India

Number of private companies engaged for producing bio fertilizers in different states of India revealed that Tamil Nadu have the highest no. public sector companies (7) and Delhi is having largest number of co-operative units (3) as indicated in Fig. 2.

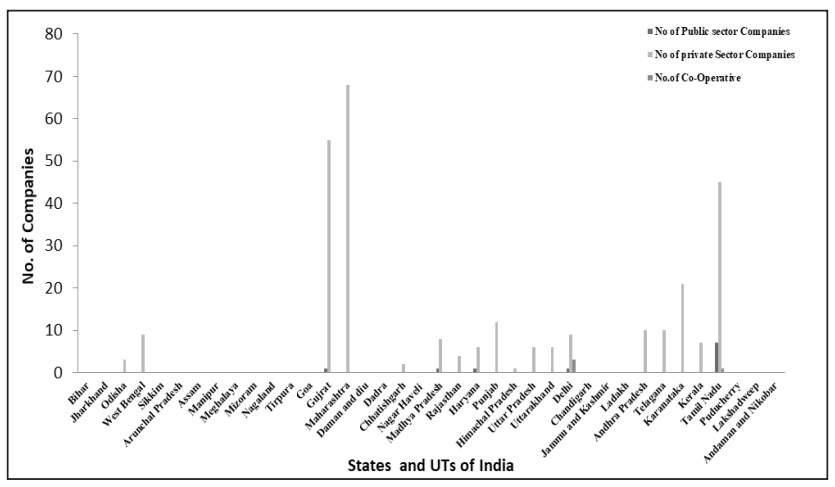

Fig. 2: Break up of different organization(public, private and co-operatives) in different states of India

Inoculant wise biofertilizer production (carrier base) (MT) in different State/UT of India during 2016-17 is highest in Gujarat i.e., 6575 MT followed by Madhya Pradesh and Karnatka 2589.9 as shown in Fig 3. Zone wise bio-fertilizer production in India during
2016-2017 highest in Karnatka both in carrier based formulation i.e., 31553.06 MT and liquid based formulation i.e., $993.443 \mathrm{KL}$ as indicated in Table 1.

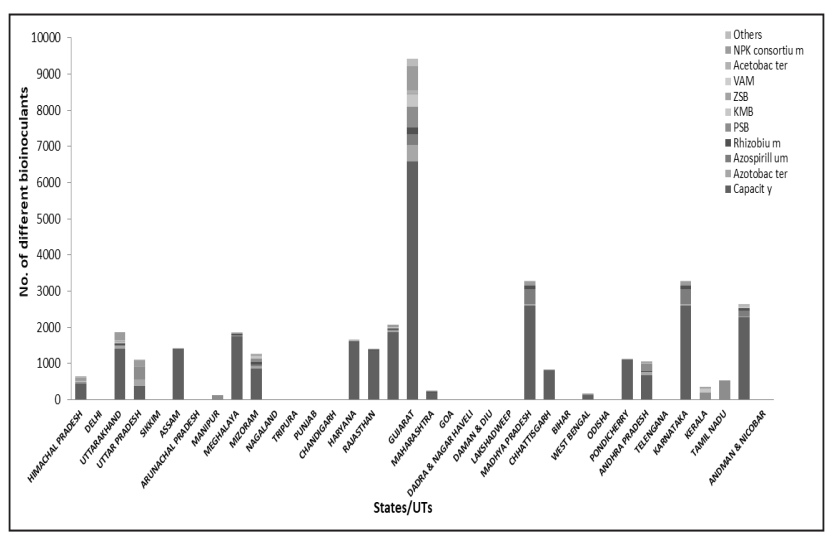

Fig. 3: Inoculant wise biofertilizer production (carrier base) (MT) in different State/UTof India during 2016-17

\section{Quality Control is a concern}

The interest in biofertilizers is also increasing due to their potential for use in sustainable agriculture. However, many of the products that are currently available worldwide are of poor quality. The formulation of an inoculant is a multistep process that results in one/several strains of microorganisms included in a suitable carrier, providing a safe environment to protect them from the harsh conditions during storage and ensuring survival and establishment after introduction into soils. A key issue informulation development and production is the quality control of the products, at each stage of the production process.

The successful application and use of biofertilizers for the agricultural system is restricted by several limitations as Non-reliable efficacy: the efficacy of most biofertilizers is doubtful, since their mechanism of action in promoting growth is not well understood, despite the extensive research in this direction; Effect of abiotic factors on biofertilizers efficacy: it is still not clear how variations in soil type, management practices and weather affect the biofertilizer efficacy; Field trials performance: It is still difficult to test inoculants in the field as routine experiments.

The quality specifications of biofertilizers differ from country to country and may contains parameters such as the microbial strain(s) used; the quality of biofertilizers is usually defined in terms of two important characteristics: presence 


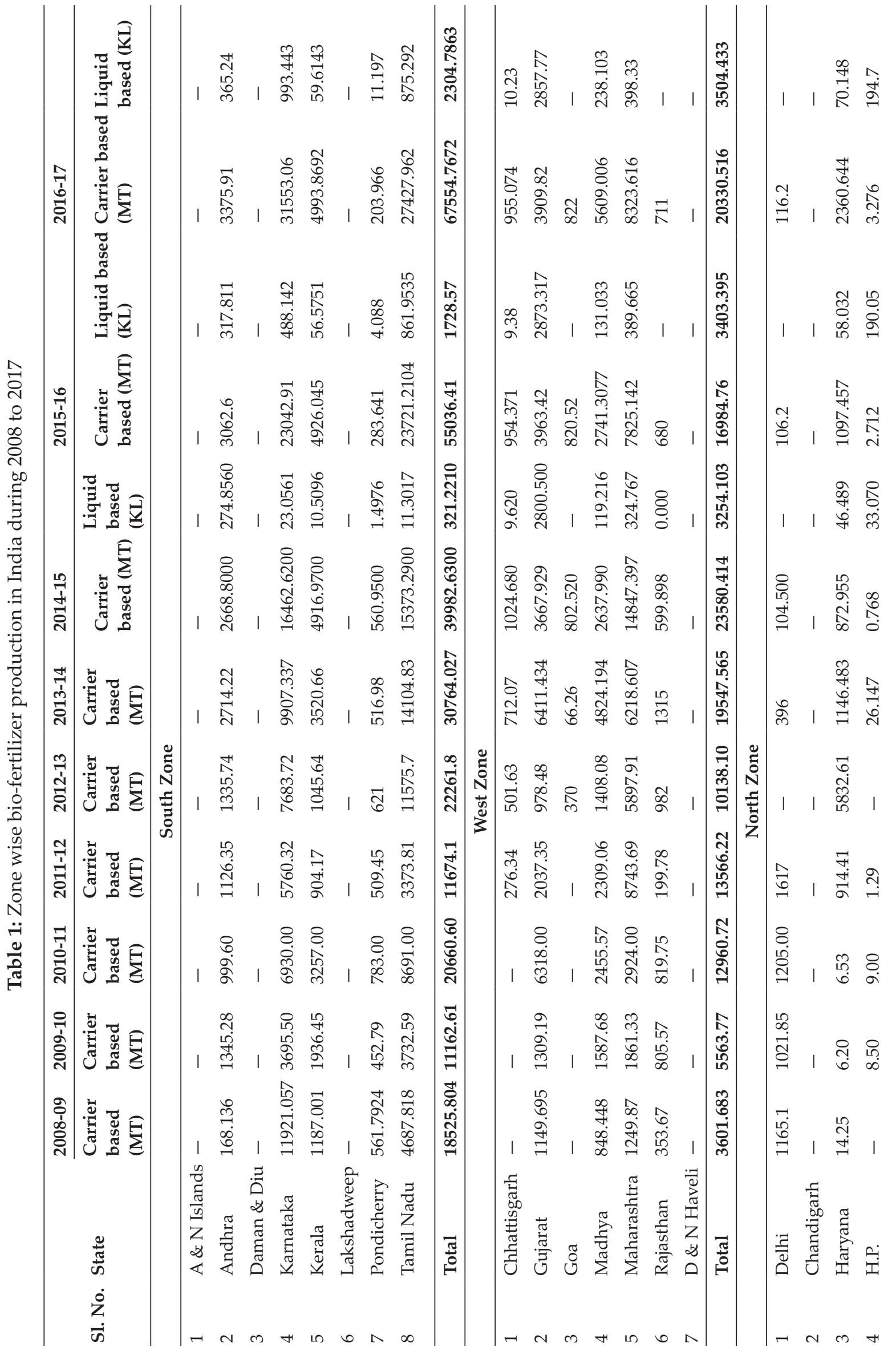


Bio-inoculants as Prospective Inputs for Achieving Sustainability: Indian Story

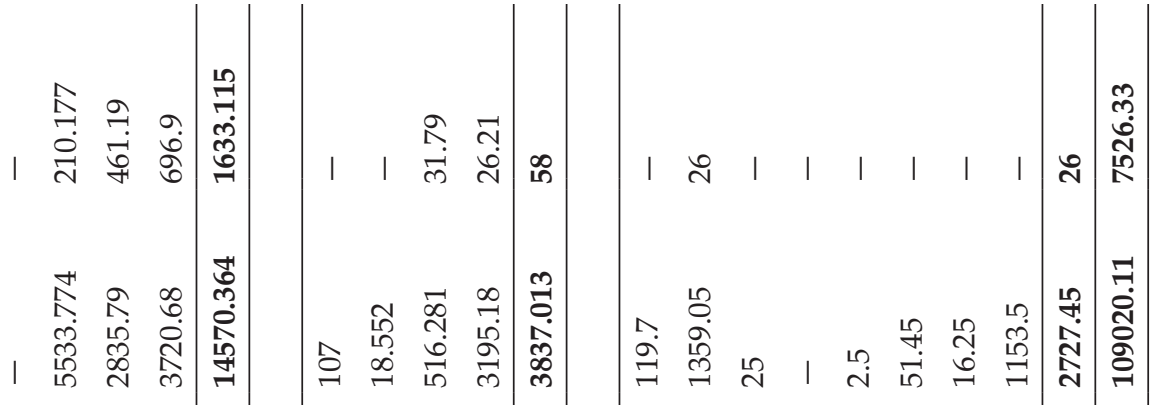

मึ

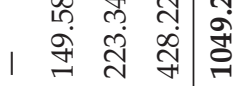

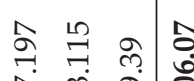

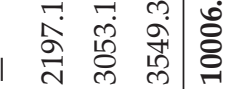

సิ

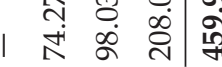

భึ

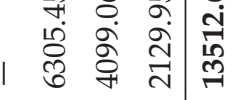

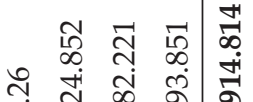

華

₹

సิ

๓ి

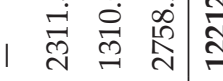

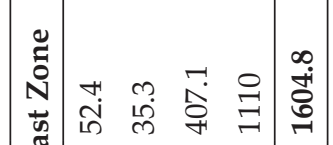

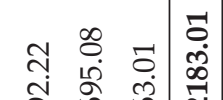

|

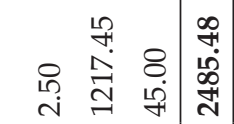

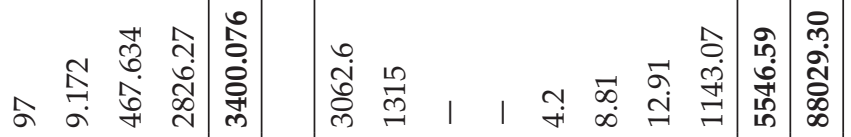

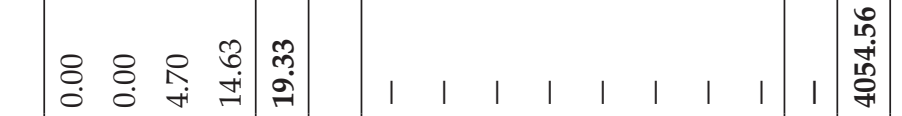

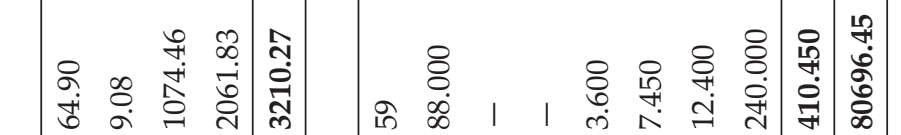

:

유유

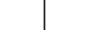

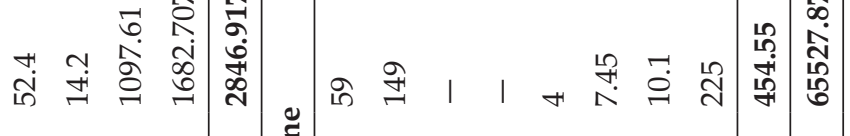

苛 1

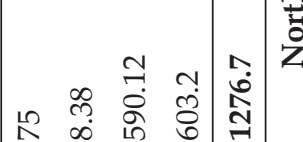

। ति बं हु

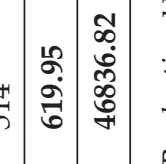

$\left.\infty \frac{1}{2}\right)$

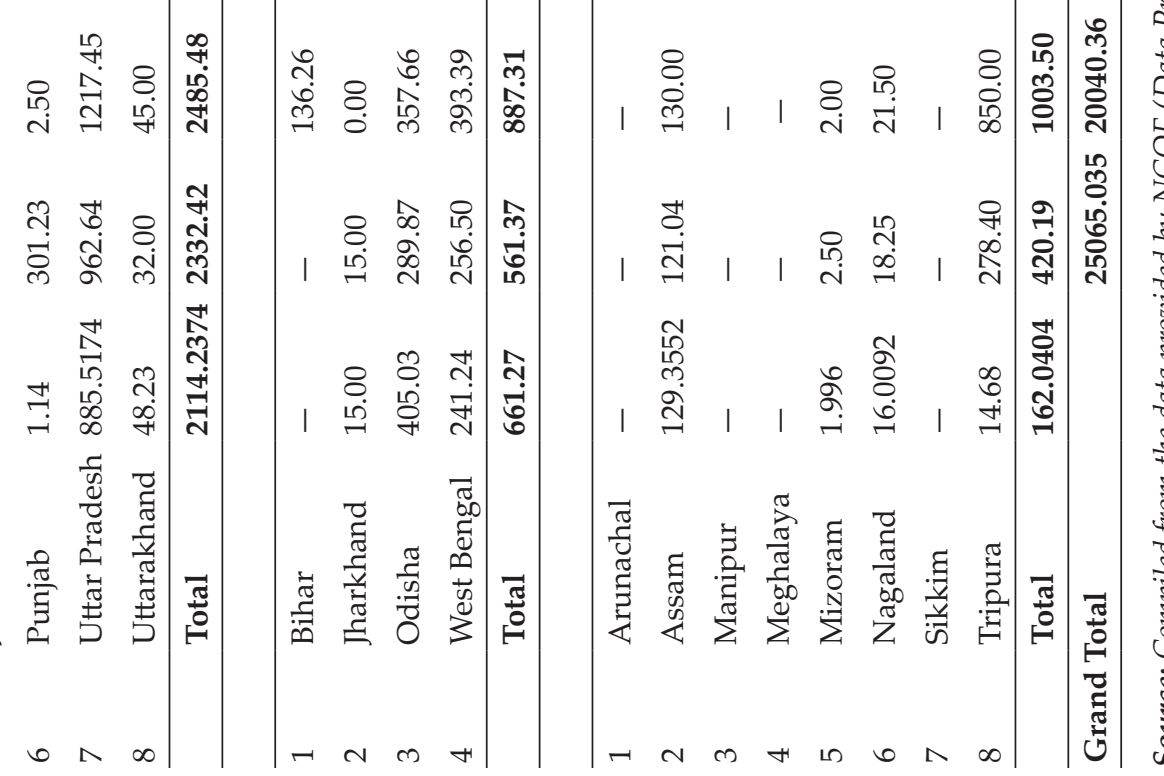

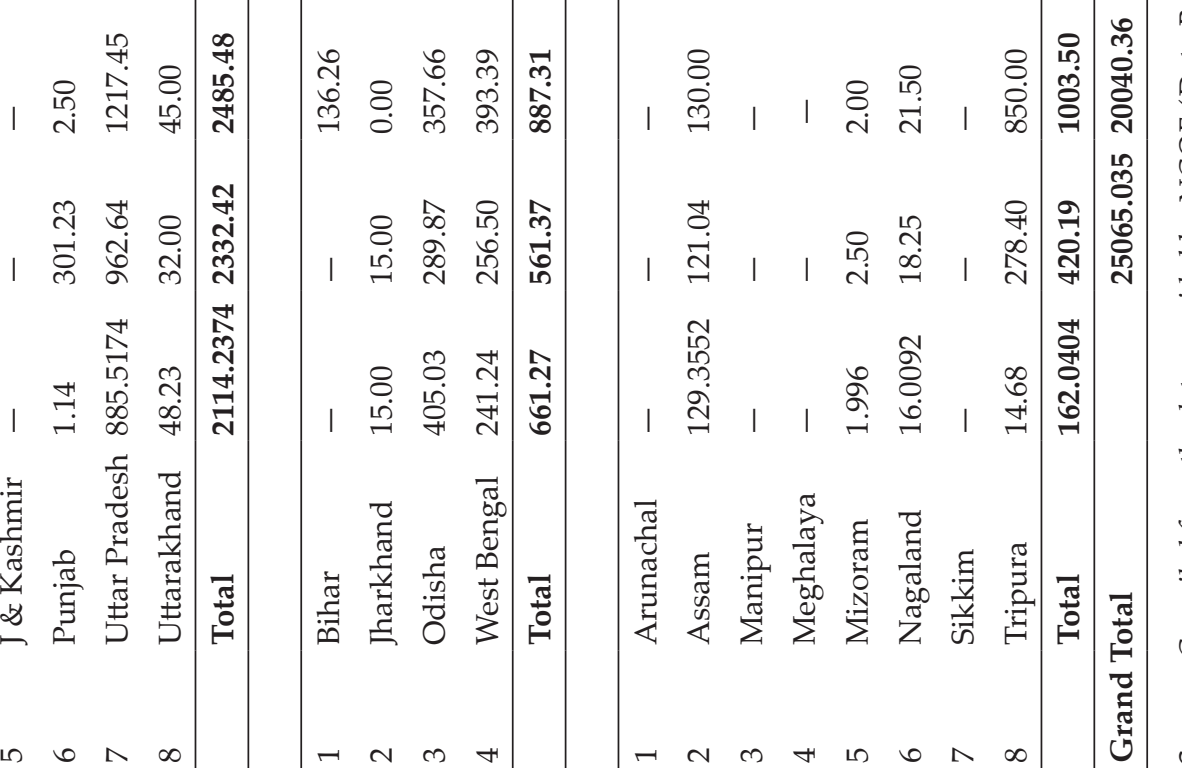

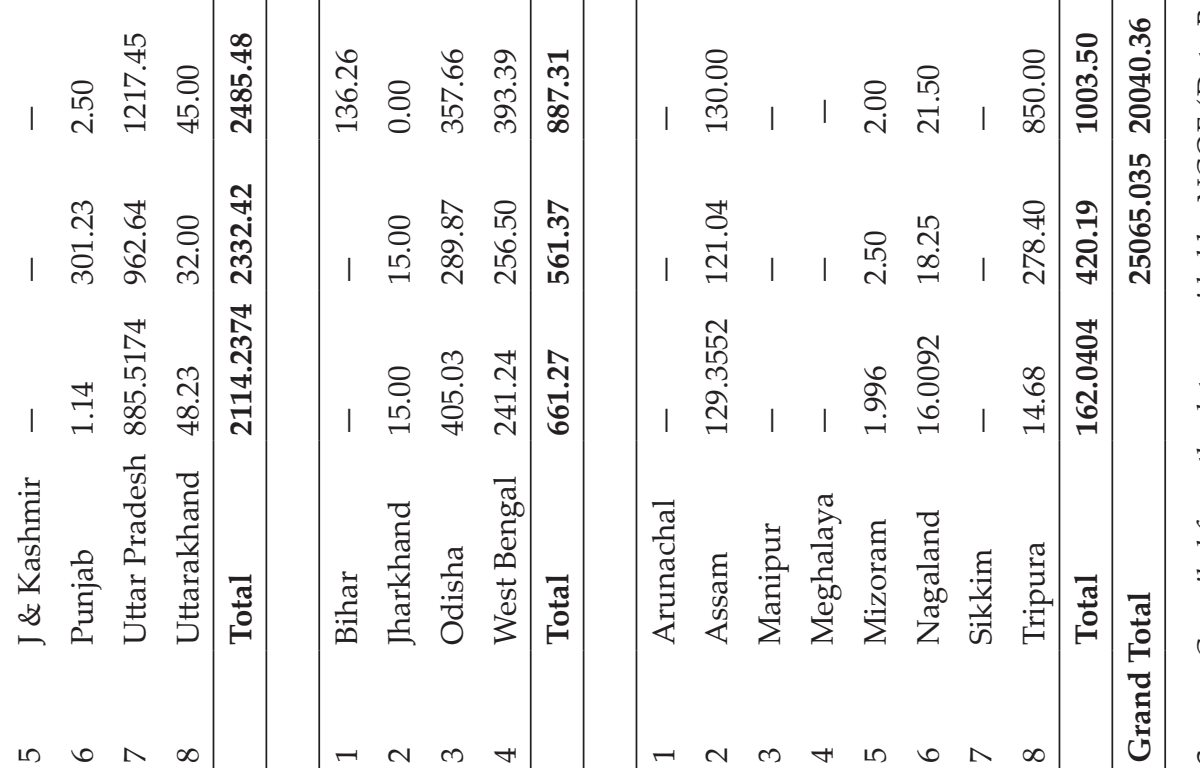


of a recommended strain in the required quantity and in active form;Microbial density at the time of manufacture and at the time of expiry: the number of selected microorganisms in the active form per gram or milliliter of biofertilizer. The guidelines used are limited to the density of the available microorganisms and their viability and preservation; the permissible contamination: it is important to set control schemes that account for putative contaminating microorganisms; the expiry period;the $\mathrm{pH}$, the moisture and the carrier; the control management is very essential and must be performed continually. The procedure of biofertilizer quality control includes guaranteed identification of the strains;guaranteed cell density of the strains; assessment of the main activities as effect indicators of biofertilizers; regular inspection for quality control by the competent authorities; evaluation of the effect on target crops; registration under the regulation.

\section{Government Initiatives}

The government of India is very proactive in cause of taking actions against the miserable conditions of agriculture sector. It has been always in the attention of the government officials to look after the fertility of soil and its health. Government of India has been implementing the scheme for the promotion of biofertilizers since $7^{\text {th }}$ Five Year Plan. Under this scheme, one national centre - NCOF and six regional centresRCOFs have been established. In 1988, under full grant-in-aid of Govt. of India OAIC (Odisha Agro Industries Corporation Limited) a Govt. of Odisha undertaking set up a bio-fertilizer production unit at Laxmisagar, Bhubaneswar. Since then the unit has been processing quality bio-fertilizers namely Rhizobium Culture, P.S.B., Azotobactor, Azospirrilum, Potash Mobilizing Bacteria (KMB) Trichoderma for compost production The unit has also been making constant effort in promoting the use of bio-fertilizer in different crops mainly in paddy, oil seed crops, pulses, vegetables, orchard crops, sugarcane and beetle leafs. In Gujarat setting up a Bio-Fertilizers and Bio-Pesticides Unit Biotechnology Government of Gujarat: Savli Biotech park, Gujarat Industrial Development Corporation (GIDC) in Vadodara district an ideal location to establish a biofertilizer and biopesticide manufacturing plant. It had developed in three phases. The site is owned and managed by GIDC and has gained traction from large fertilizer and pesticide companies including GSFC and Bayer.

Entrepreneurship Development Programme" In Biotechnology Sponsored by Development Commissioner Small Scale Industries(DCSSI) Government of India \& Department of Biotechnology (DBT), Government of India Conducted by Biotech Consortium India Limited (BCIL), New Delhi \& Small Industries Service Institute, Mumbai. The present information contains on technical and general aspects of management of biotechnology projects such as biofertilizers, biopesticides, enzymes, micropropagation, organic farming, medicinal plants extraction, immuno-diagnostics, prawn culture, prawn hatchery, pearl aquaculture, nutraceuticals and solid waste management for biotech products. This document has been put together by BCIL in association with EKTA Incubation Center (WBUT) under the guidance of DBT and DCSSI, Government of India to create awareness about the management of biotechnology projects among the prospective entrepreneurs.

National Project on Organic Farming (NPOF) is a continuing central sector scheme since 10th Five Year Plan. Planning Commission approved the scheme as PILOT project for the remaining two and half years of $10^{\text {th }}$ plan period with effect from 01.10.2004 with an outlay of ₹ 57.04 crore. The scheme is continuing in the $12^{\text {th }}$ Plan. NPOF is being implemented by National Centre of Organic Farming at Ghaziabad and its six Regional Centres. Besides working for realisation of targets under NPOF, NCOF and RCOFs are also performing specific roles in promotion of organic farming and having some objectives to be aimed by these institutions such as promotion of organic farming in the country through technical capacity building of all the stakeholders including human resource development, transfer of technology, promotion and production of quality organic and biological inputs; awareness creation and publicity through print and electronic media; to act as nodal quality control laboratory for analysis of biofertilizers and organic fertilizers as per the requirement of Fertilizer Control Order (FCO, 1985); revision of standards and testing protocols keeping in view the advances in research and technology and bringing remaining organic inputs under quality control regime; 
Bio-inoculants as Prospective Inputs for Achieving Sustainability: Indian Story

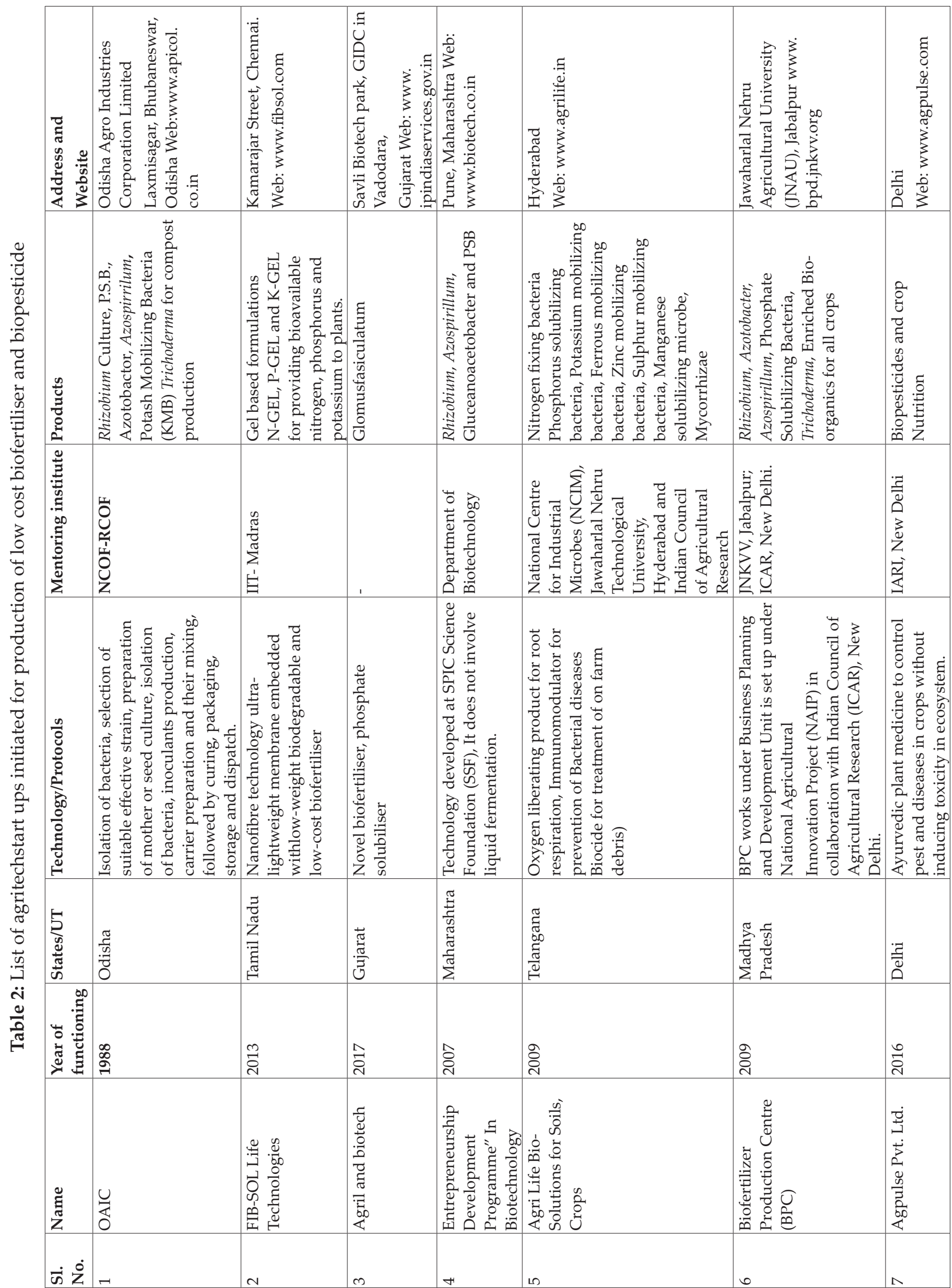


$\underset{\text { AEssseA }}{\llbracket}$ Gupta et al.

\begin{tabular}{|c|c|c|c|c|c|c|c|c|c|}
\hline 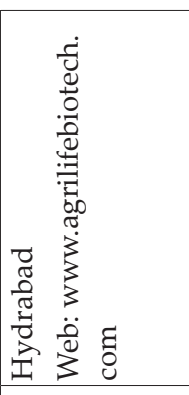 & 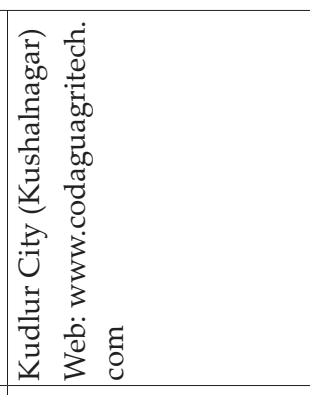 & 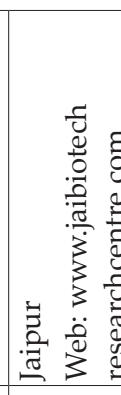 & 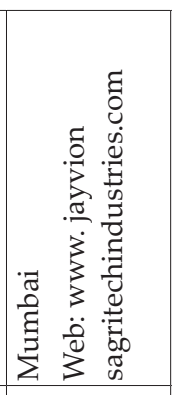 & 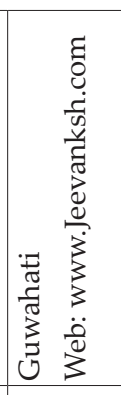 & 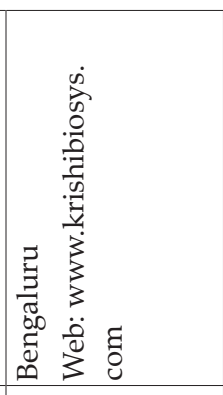 & 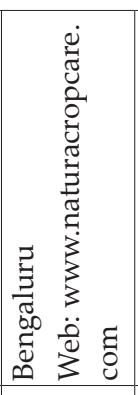 & 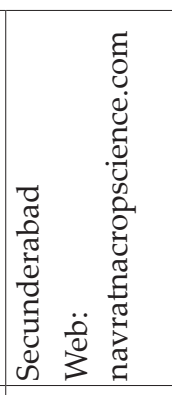 & 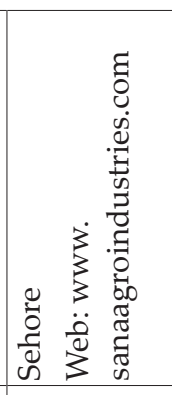 & 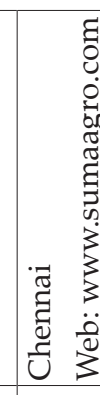 \\
\hline 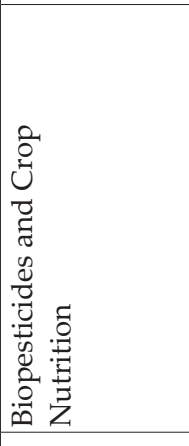 & 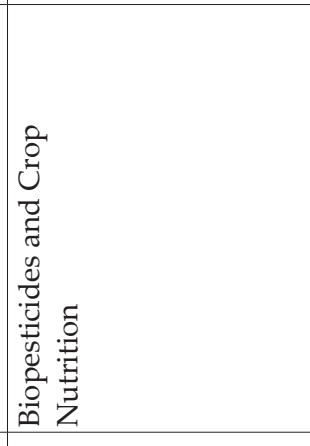 & 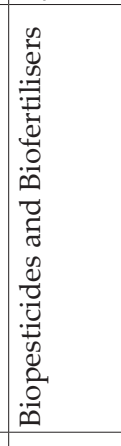 & 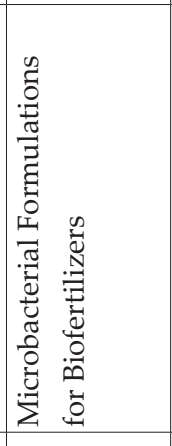 & 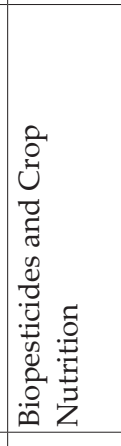 & 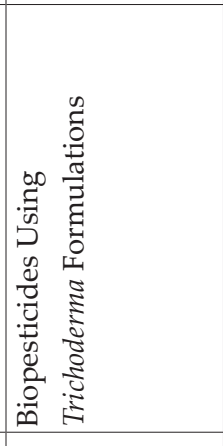 & 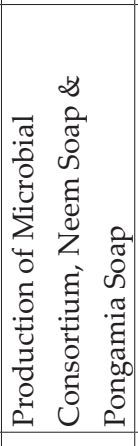 & 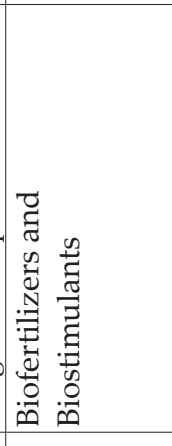 & 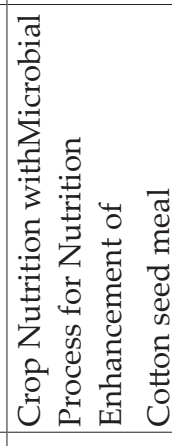 & 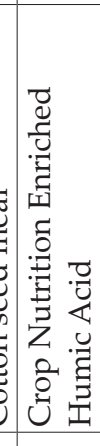 \\
\hline 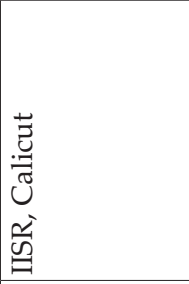 & 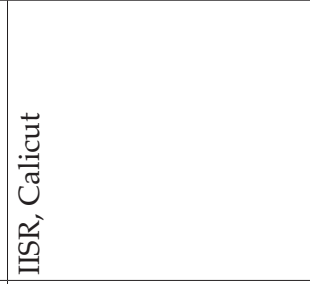 & 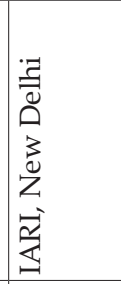 & & 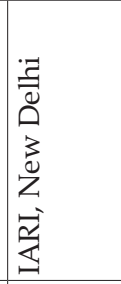 & 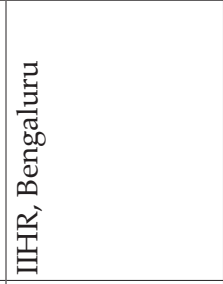 & 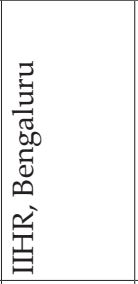 & 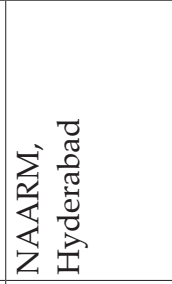 & 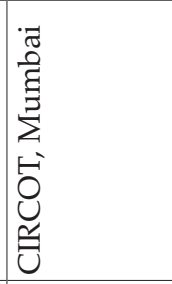 & 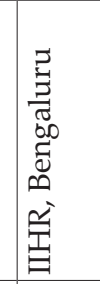 \\
\hline 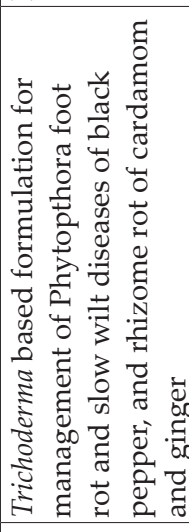 & 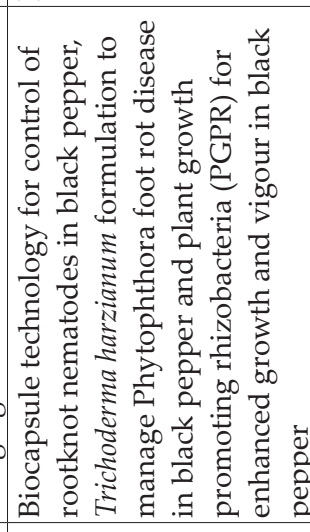 & 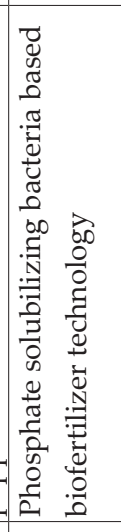 & 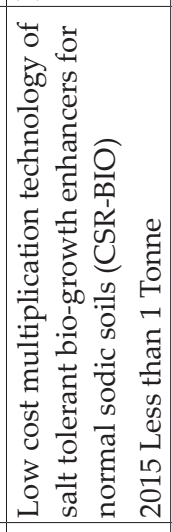 & 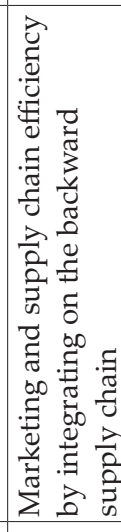 & 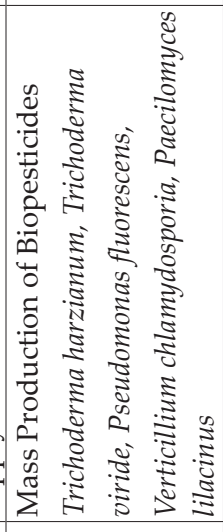 & 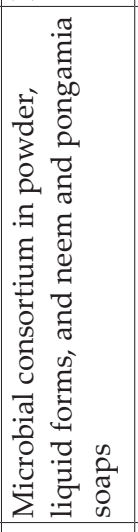 & 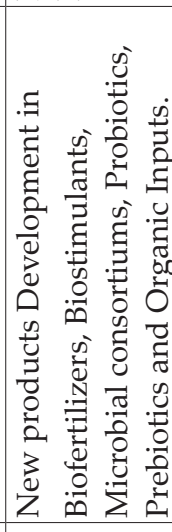 & 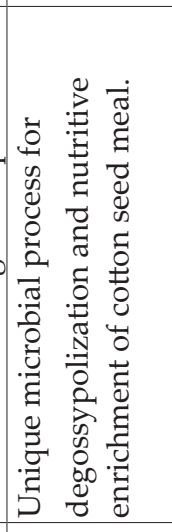 & 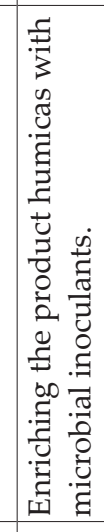 \\
\hline 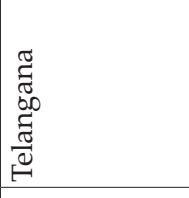 & 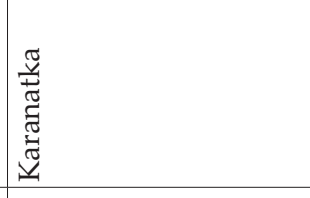 & 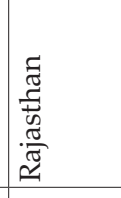 & 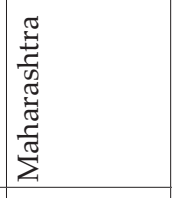 & 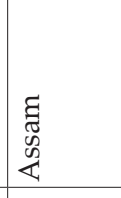 & 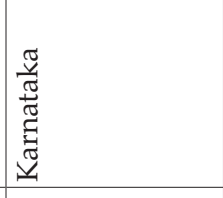 & 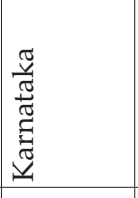 & 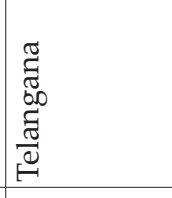 & 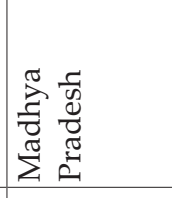 & 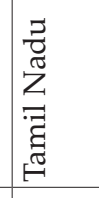 \\
\hline तू & त̈: & పై & ते & స్ & $\overrightarrow{\widetilde{d}}$ & 芩 & స్ & $\widehat{\vec{N}}$ & तี \\
\hline 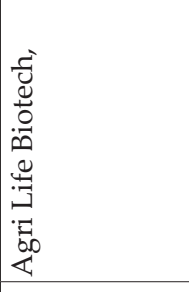 & 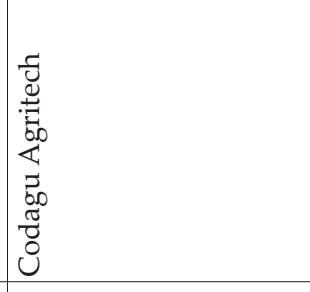 & 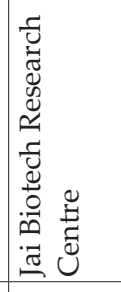 & 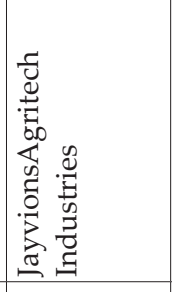 & 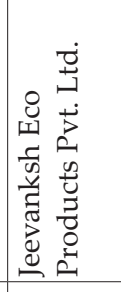 & 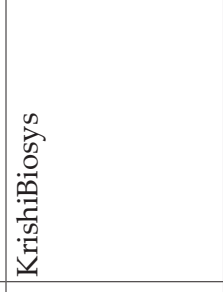 & 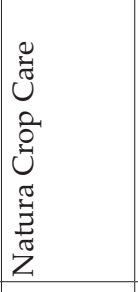 & 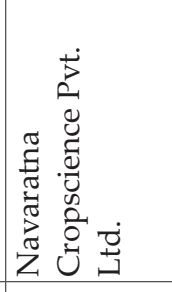 & 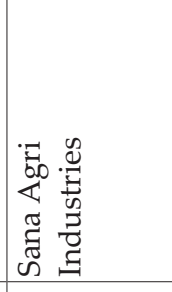 & 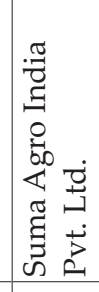 \\
\hline & a & $\stackrel{ }{ }$ & $F$ & $\simeq$ & 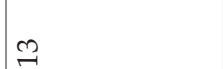 & $\nexists$ & $\stackrel{2}{\rightarrow}$ & $\stackrel{0}{\circ}$ & 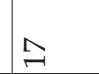 \\
\hline
\end{tabular}




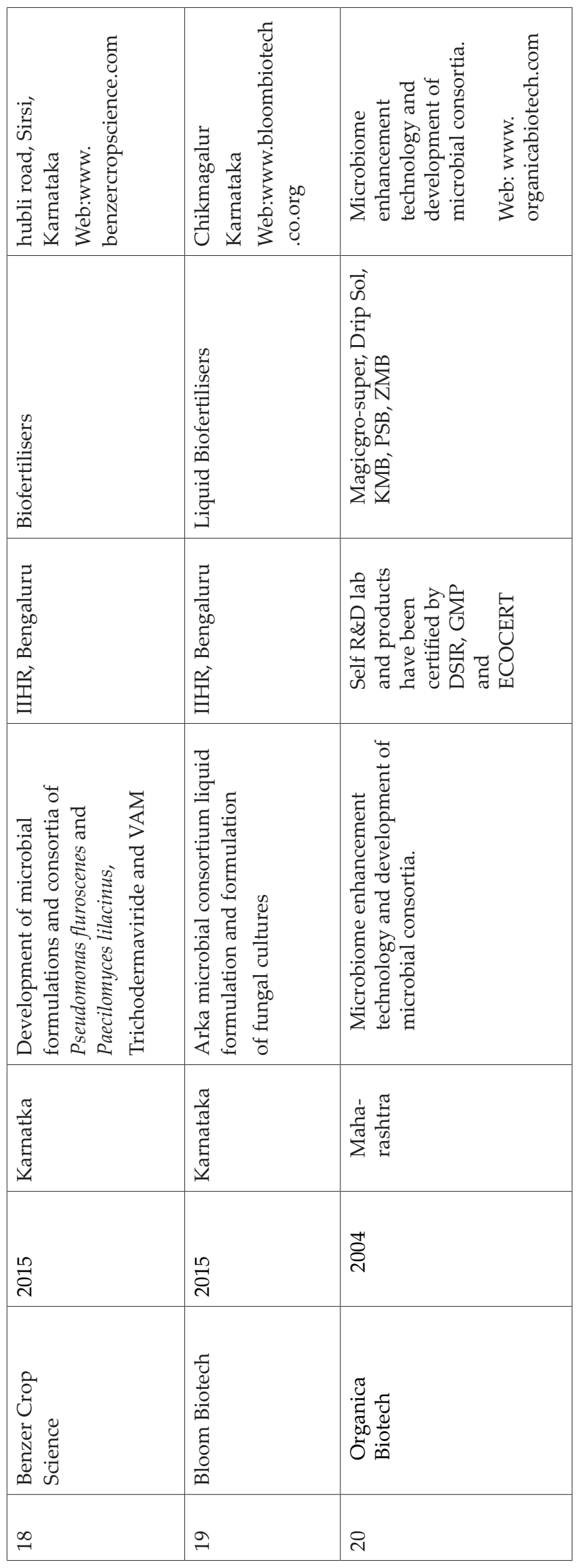


organic input resource management, technology development through support to research and market development; to maintain National and Regional culture collection bank of biofertilizer, biocontrol, waste decomposer organisms for supply to production units, development \& procurement and efficacy evaluation of biofertilizer strains and mother cultures; promotion of organic farming through low cost certification system known as "Participatory Guarantee System". NPOF scheme provides financial assistance through Capital Investment Subsidy Scheme (CISS) for agrowaste compost production units, bio-fertilizers/ bio-pesticides production units, development and implementation of quality control regime, human resource development, etc.

\section{CONCLUSION}

Uncontrolled over-application of chemical fertilizers by farmers during intensive agricultural practices has led to excess nutrients (particularly $\mathrm{P}$ ) accumulation in soils, which, as a result, makes the soils dead. That is why, nowadays, the production of efficient and sustainable biofertilizers for crop plants, wherein inorganic fertilizer application can be reduced significantly to avoid further pollution problems, represents major research interest. It comprises undertaking short-term, medium and long-term research programmes combining the efforts and scientific potential of soil microbiologists, agronomists, plant breeders, plant pathologists, nutritionists and economists to work together. Successful promotion of biofertilizers technology in sustainable agriculture depends on implementation of programmes for raising awareness among the biofertilizers producers and consumers. Biofertilizers are apparently an environmentally sound and farmer-friendly renewable source of low cost agro-input. However, bioinoculants, especially those regarded as broad spectrum biofertilizers (Azotobacter, Azospirillum, phosphate-solubilizing bacteria and Arbuscular mycorrhizal fungi) have not received the deserved attention.

Considering at the worldwide market it is evident that during 2018, the demand for biofertilizers were anticipated to exceed a market worth of US\$ 10.2 billion. The top consumers of biofertilizers were Europe and Latin America, mainly because in the countries from these regions, there were stringent regulations imposed on chemical fertilizers. These were followed by Asia-Pacific, which controlled more than $35 \%$ of the market. Looking at the present perspective and growing awareness for organic farming for restoring natural resource base authenticated inventorisation is key. The total number of units involved in technology making and its legitimations, their product's, productions and productivity, their demand in present and need in future, development of initiatives, startups and entrepreneurships their availability of resources as well-warrant digitization. Although efforts have been started from seventh five year plan but taking advantage of proactive government set up it is high time to streamline the informations for a greater cause and revival of fresh initiative.

\section{ACKNOWLEDGMENTS}

The authors would like to thank the anonymous reviewers for their insightful suggestions. This research was supported by the DST -NSTIMS, Government of India [grant number NSTIMS /05/315/2017-18].

\section{REFERENCES}

Banerjee, A., Bareh, D.A. and Joshi, S.R. 2017.Native microorganisms as potent bioinoculants for plant growth promotion in shifting agriculture (Jhum) systems. Journal of Soil Science and Plant Nutrition, 17(1): 127-140.

Barman, M., Paul, S., Choudhury, A.G., Roy, P. and Sen, J. 2017. Biofertilizer as prospective input for sustainable agriculture in India. International Journal of Current Microbiology and Applied Sciences, 6: 1177-1186.

Bhardwaj, D., Ansari, M.W., Sahoo, R.K. and Tuteja, N. 2014. Biofertilizers function as key player in sustainable agriculture by improving soil fertility, plant tolerance and crop productivity. Microbial Cell Factories, 13(1): 66.

Dash, S. and Gupta, N. 2011. Microbial bio-inoculants and their role in plant growth and development. International Journal of Biotechnology and Molecular Biology Research, 2(13): 232-251.

Elsebaay, H. and Elkotkat, M.B.O. 2011. Effect of bioinoculation, compost and farmyard manure addition on common bean plant. Journal of Agricultural Chemistry and Biotechnology, 2(9): 175-183.

Firuzsalari, S.M., Mirshekari, B. and Khochebagh, S.B. 2012. Effect of seed inoculation with bio-fertilizer on germination and early growth of corn. Int Res J App Basic Sci., 3: 1097-102.

Meena, S.K., Amitava Rakshit, Harikesh B Singh, Vijay Singh Meena. 2017. Effect of nitrogen levels and seed bio- 
priming on root infection, growth and yield attributes of wheat in varied soil type. Journal Biocatalysis and Agricultural Biotechnology, 12: 172-178.

Nehra, V. and Choudhary, M. 2015. A review on plant growth promoting rhizobacteria acting as bioinoculants and their biological approach towards the production of sustainable agriculture. Journal of Applied and Natural Science, 7(1): 540-556.

Parween, T., Bhandari, P., Jan, S., Fatma, T. and Raza, S.K. 2017. Role of Bioinoculants as Plant Growth-Promoting Microbes for Sustainable Agriculture. In Agriculturally Important Microbes for Sustainable Agriculture (pp. 183206).Springer, Singapore.

Raja, K., Anandham, R. and Sivasubramaniam, K. 2019. Infusing microbial consortia for enhancing seed germination and vigour in pigeonpea (Cajanus cajan (L.) Millsp.). Legume Research - An International Journal, 42(3): 334-340.
Res, I.J.E.S.N. 2017. Effect Bio-Inoculants and Organic Supplementation a Growth and Yield of Pomegranate. Pomegranate, 4(4): 555641.

Selvakumar, G., Panneerselvam, P., and Ganeshamurthy, A.N. 2014. Biosafety of novel bioinoculants. Journal of Biofertilizers \& Biopesticides, 5(2): 1.

Suman, A., Verma, P., Yadav, A.N., Srinivasamurthy, R., Singh, A. and Prasanna, R. 2016. Development of hydrogel based bio-inoculant formulations and their impact on plant biometric parameters of wheat (Triticum aestivum L.). Int. J. Curr. Microbiol. Appl. Sci., 5(3): 890-901.

Tiyagi, S.A., Rizvi, R., Mahmood, I. and Khan, Z. 2015. Evaluation of organic matter, bio-inoculants and inorganic fertilizers on growth and yield attributes of tomato with respect to the management of plant-parasitic nematodes. Emirates Journal of Food and Agriculture, pp. 602-609. 
